\title{
Entre a lógica da formação e a lógica das práticas: a mediação dos saberes pedagógicos
}

Maria Amélia Santoro Franco

Universidade Católica de Santos

\begin{abstract}
Resumo
0 trabalho procura colocar em destaque as diferentes concepções que sustentam a lógica que preside as práticas docentes e aquela que organiza os processos formativos, para então considerar que os saberes pedagógicos, vistos como saberes estruturantes do conhecimento profissional, podem ser o elo necessário para produzir os diálogos entre essas duas instâncias que coexistem na prática social de formação de docentes, embora, muitas vezes, de forma desconectada. A seguir, propõe-se a analisar as possibilidades da prática como elemento constitutivo e fecundador da formação docente. Coloca em destaque diferentes concepções de prática, realçando que há uma prática que forma, informa e transforma, simultaneamente, o sujeito e suas circunstâncias, e há uma prática que oprime, distorce e congela, especialmente 0 sujeito que nela se exercita e, nesse caso, este perde 0 acesso às suas circunstâncias. Realça estudos e pesquisas que demonstram que a prática é sempre mais abrangente do que aquilo que se supõe à primeira vista e sempre menos inteligível do que seria necessário considerar. Propõe a superação do sentido tecnicista que acompanha a representação dos estágios supervisionados para uma dimensão de práticas de formação que se organizem em novas unidades de sentido, que sirvam para configurar e sustentar a nova identidade profissional do professor para atuar na escola pública contemporânea.
\end{abstract}

\section{Palavras-chave}

Formação - Prática docente - Saberes pedagógicos. 


\title{
Between the logic of formation and the logic of practices: the mediation of pedagogical knowledges
}

Maria Amélia Santoro Franco

Universidade Católica de Santos

\begin{abstract}
The text seeks initially to call attention to the different conceptions that underlie the logic presiding over the teaching practices, and that organizing the formative processes. It goes on to propose that the pedagogical knowledges, seen as structuring elements of the professional knowledge, can be the necessary link to produce the dialogues between those two instances, which coexist in the social practice of teacher education, albeit often in an unconnected way. The article then tries to analyze the possibilities of practice as a constitutive and fertilizing element of teacher education. The work highlights the different ideas of practice, observing that there is a practice that simultaneously forms, informs, and transforms the subject and his/her circumstances, and there is a practice that oppresses, distorts and congeals the subject under it, and in this case the subject can lose touch with his/her circumstances. The article shows studies and researches that demonstrate that practice is always wider than initially supposed, and always less intelligible than it was necessary to assume. It proposes to overcome the technicist meaning that currently attends the representation of supervised internships, toward education practices organized into new units of meaning that contribute to shape and sustain a new teacher professional identity fit to play a role in contemporary public schools.
\end{abstract}

Keyw ords

Formation - Teacher practice - Pedagogical knowledges.

Contact:

Maria Amélia Santoro Franco

Rua Campevas, 206 - Perdizes

05016-010 - São Paulo - SP

e-mail: ameliasantoro@uol.com.br 
Em sucessivos trabalhos e pesquisas sobre a formação inicial e continuada de docentes, quer nos cursos de Pedagogia, quer nas diferentes licenciaturas ou ainda em programas e projetos de formação continuada de professores, pude constatar, entre outras coisas, que a prática pode ser tanto uma circunstância para transformar a própria prática e os sujeitos que dela participam como, paradoxalmente, a prática pode ser, também, a circunstância para reificar a própria prática e, assim, blindar 0 sujeito, impedindo-o de receber da prática seus ingredientes fertilizantes e formadores.

Percebi, trilhando os complexos caminhos de formadora de docentes, que há uma prática que forma, informa e transforma, simultaneamente, o sujeito e suas circunstâncias, e há uma prática que oprime, distorce e congela, especialmente o sujeito que nela se exercita e, nesse caso, este perde 0 acesso às suas circunstâncias. Percebi nesse processo que a prática é sempre mais do que aquilo que se supõe à primeira vista e sempre menos inteligível do que seria necessário considerar.

Percebi ainda que os sentidos que as concepções tecnicistas foram atribuindo à prática foram sempre bem-recepcionados e bemvindos na estrutura de uma sociedade capitalista, pragmatista, muito distante dos sentidos de prática expressos por Marx; e assim, a prática de formação, a prática que chamo de pedagógica, foi se estruturando também de forma tecnicista, no pressuposto de que não há um sujeito que possa/deva criar e transformar suas circunstâncias, mas no pressuposto de que esse sujeito, independentemente do que pensa e sinta, precisa realizar certas tarefas de um determinado jeito, considerado o ideal por algumas esferas de decisão anteriores.

O sentido de formação prática, que historicamente permeou os percursos formativos no Brasil, não tem como pressuposto libertar o sujeito para que este se aproprie de suas circunstâncias e perceba as possibilidades de criar seu fazer em sintonia com os sentidos de sua existência histórica. Esse sentido impregnou os procedimentos utilizados no processo formativo e a prática sob forma de estágio supervisionado, e foi sendo utilizado para que o sujeito, reificado em sua condição de não diálogo com suas circunstâncias, permaneça não estabelecendo relações de sentido entre ser e fazer, mas mesmo assim, aprenda a reproduzir um fazer considerado necessário. 0 pressuposto é que esse sujeito é incapaz de criar sentido à sua atividade produtiva, no caso o fazer docente.

Essa situação, decorrente da concepção de prática como treinamento do fazer, é um dos componentes que podem ajudar a compreender o desconforto de formandos, futuros professores, nos primeiros confrontos com as atividades da prática docente: são situações sempre angustiantes, pois as receitas de fazer que receberam no processo formativo não Ihes permite colocar em prática as expectativas que haviam construído a respeito de um ensino melhor. Essa realidade é permeada por dissonâncias, o que pode demonstrar que o sujeito não está totalmente 'engessado' por suas condições formativas, pois ainda é capaz de estranhar. Esse estranhamento, essa perplexidade é um espaço da possibilidade pedagógica: o estranhamento, a angústia, as dissonâncias demonstram que há ainda um espaço para a construção de um fazer significativo. Há um espaço para que as práticas comecem a falar, a informar, a formar. Há um espaço para transformação das práticas em instrumentos pedagógicos de formação. No entanto, há também um espaço para a negação dessa possibilidade. Na dissonância, o sujeito pode optar por abandonar suas expectativas e seus desejos e conformar-se com o usual. 0 sujeito liberta-se do estranhamento em favor de uma segurança com o familiar.

É disso que queremos falar neste texto: compreender as lógicas das práticas para transformá-las em possibilidades formativas que, na sua relação, constituem-se em saberes orientadores do fazer que não se deixa render exclusivamente à cultura escolar de orientação tecnicista e dá ao professor a possibilidade de munir-se de um conjunto de elementos que po- 
dem responder, criativamente, aos problemas enfrentados no cotidiano escolar.

São complexos os caminhos que organizam a lógica das práticas, e percebi que essa lógica não muda por decreto, mas talvez mude por compreensão, por confronto ou por superação. Por várias ocasiões, coordenando cursos de Pedagogia, tentei alterar a situação dos formandos frente ao estranhamento com a prática: ora modificava a matriz curricular, ora diversificava as atividades de estágios, muitas vezes buscava a inserção de atividades culturais complementares, mas mesmo assim, os primeiros encontros dos alunos com as situações de prática eram, no mínimo, frustrantes: quer como observadores da prática alheia, quer como docentes- protagonistas da aula ou mesmo participantes de diversas rotinas escolares, sentiam-se acuados pelo impacto de um fazer rotineiro, mecânico, sem sentido, alienado e alienante. Os futuros professores não queriam isso para si, mas desde já percebiam que furar essa racionalidade das práticas não era tarefa para principiantes.

Quando estive como diretora de escola pública (Franco, 1996) por onze anos consecutivos, pude mergulhar um pouco mais fundo nos meandros da prática docente confinada nos poucos espaços de autonomia que Ihe restam, premida por condições opressoras, que alijam possibilidades de inovação, de motivação e de criação no ambiente escolar. Nesse olhar profundo e cotidiano de educadora-pesquisadora, percebi na prática algumas possibilidades de transformar o fazer docente, começando por oferecer ao professor as condições de se fazer como sujeito da história e protagonista de seu tempo e de seu trabalho. Descobri que a prática docente tinha uma outra lógica, seguia e decorria de pressupostos construídos ao longo da existência do ser. Descobri que a prática organiza-se em torno de diferentes epistemologias e tenho me debruçado (Franco, 2003; 2005; 2006) na compreensão das estruturas e dos processos que organizam a prática como práxis, superando sua contextualização como tecnologia.
Lisita (2006), ao realizar uma metarreflexão a partir de um trabalho de pesquisa-formação que realizou na tentativa de observar as possibilidades de diálogos entre os saberes da prática e os saberes da formação, afirma que percebeu a existência de duas lógicas que, ao longo do processo vivido no grupo de aprendizagem, ora se aproximaram, ora se distanciaram: a lógica das práticas e a lógica da formação ${ }^{1}$.

Diz a autora que enquanto a lógica das práticas era pautada pela necessidade de conhecer para atuar, isto é, para ensinar no contexto das demandas e urgências da prática, a lógica da formação era regida por questões de conhecimento, nem sempre vinculadas às demandas imediatas do exercício da profissão de ensinar. Lisita refere-se a processos formativos que querem romper com a racionalidade de oferecer receitas para as urgências da prática, mas que são pouco significativos para aqueles docentes que têm à sua frente a urgência dos problemas cotidianos. Nessa contradição é que essas lógicas se configuram.

É sabido que os modelos de formação, tal qual ocorrem na maioria das agências formadoras de docentes, fragmentam o processo formativo, dando a falsa impressão de que os futuros professores precisam se apropriar de teorias para poder aplicá-las na prática.

Tenho também observado que os modelos de formação, muito comuns em processos de formação continuada, que pretendem a alteração mecânica das práticas, sob forma de treinamento de habilidades e competências, têm conseguido, quando muito, alterar a espontaneidade do saber fazer intuitivo, conduzindo o professor a mecanismos de insegurança e apatia na busca de novas propostas de organizar seu saber fazer.

Conhecer essas lógicas significa caminhar na direção de estudos e pesquisas que

1. Para a autora, o sentido de lógica é o de caminhos 'construídos' pelo pensamento para abarcar (explicar, compreender) a realidade, de acordo como esta se apresenta com sentido para o sujeito. Ela se pautou em Charlot (1990) para estruturar esse conceito. Neste texto, acompanho o sentido construído pela autora. 
aprofundam análises sobre a práxis docente, referendando que apenas nas mediações do sujeito com seu fazer é que a pratica se torna inteligível ${ }^{2}$.

Para caminhar nessa direção, será preciso refinar o sentido de prática, os pressupostos que acompanham os discursos sobre a formação docente e também analisar a prática desses pressupostos nos espaços formativos.

Volto a reafirmar neste texto que os fundamentos da ciência pedagógica são fundamentais à construção de saberes pedagógicos (Franco, 2006) que poderão funcionar como 'passarelas' a intermediar e produzir diálogos entre essas diferentes lógicas.

Há ainda que se realçar que o processo de formação de docentes ocorre tanto em espaços formalmente constituídos para tal fim, como também em diferentes circunstâncias que confluem e estão presentes no processo formal de formação. Pode-se até afirmar que a mediação entre essas duas dimensões de formação - a formal e a espontânea - constitui-se em um terceiro espaço, que deve ser considerado por aqueles que atuam com o processo formativo.

Neste artigo, o foco será a formação intencionalmente organizada para fins de preparar 0 futuro professor para o exercício de sua prática profissional, direcionada para a concretização do processo ensino-aprendizagem e contextualizada para diferentes níveis de escolaridade.

\section{A lógica das práticas}

A formação de professores tem passado por um difícil processo para se adequar às mudanças na representação social do professor, que há décadas carregava um ethos social de vocação, de missão, tarefa privilegiada no contexto cultural, para hoje absorver o sentido de uma prática profissional organizada em torno de saberes científicos, realizada por assalariados, em crescente processo de desprestígio e de pauperização. Ao lado disso, a rede de ensino passou a conviver com a complexidade de absorver uma diversidade de usuários, de diferentes camadas sociais, o que vem exigindo, dessa área de formação, crescentes e profundas reflexões sobre as necessidades e demandas dessa formação. 0 professor - que por séculos foi visto como aquele que detém um saber suficiente para ser transmitido a alunos selecionados pela pirâmide social, aplicador de procedimentos metodológicos, gerenciador de disciplina - passa a ser requisitado como um profissional crítico e criativo, pesquisador de sua prática, envolvido com questões político-sociais, numa perspectiva de inclusão de toda diversidade cultural emergente, para concretizar os ideais de uma educação inclusiva, democrática, participativa.

Premido por essas contradições, apequenado por processos formativos que não têm dado conta dessa complexidade, o professor comparece às escolas para o exercício de sua prática. Que prática é essa que ele pode ou deve desempenhar? Como, de repente, contrapondo-se à lógica das relações sociais contemporâneas, está esse professor se organizando para dar conta de ser reflexivo, criativo e pesquisador?

Sabe-se que a atividade docente não é exterior às condições sociais, psicológicas, emocionais, culturais do professor, ou seja, é um processo em que as dimensões pessoais e culturais dos professores interferem, modificam e compõem as condições de sua prática.

Assim, quero realçar que a atividade prática docente não se circunscreve no visível da prática pedagógica em sala de aula. A prática, como se sabe, não se realiza apenas nos procedimentos didático-metodológicos utilizados pelo professor. Para além das práticas aninhadas, discutidas por Sacristán (1999), há todo um sistema de representações coletivas e configurações pessoais que determinam as decisões do docente frente às demandas institucionais, organizacionais. Se de um lado pode-se considerar que o professor é um modelador da prática, "há que se reforçar que 0 docente não define a prática, mas sim 0 papel que aí ocupa" (p. 74). A lógica da prática só começa a ser desvelada a partir da considera-

2 . Essa questão pode ser vista e aprofundada na reflexão de Cunha (1989 1999), Zeichner (1993), Carr (1996), Pimenta (1994; 1998; 1999), Franco (2006), entre outros. 
ção desse lugar que o docente 'escolheu' ou foi escolhido para ocupar.

Quando tenho trabalhado com docentes (Abdalla; Franco, 2003), investigando as relações que estabelecem com as práticas que desenvolvem, percebo que estes se colocam em relação de submissão às práticas que desenvolvem, num sentido de renderem-se às exigências e possibilidades institucionais. Consideram que o conhecimento científico que supostamente aprenderam não é suficiente para dar conta da imprevisibilidade da realidade educativa. Fica reforçada a perspectiva de que a prática docente, como uma prática histórica, socialmente organizada, não se realiza por meio da aplicação de conhecimentos teóricos, científicos e pedagógicos.

Essa situação reforça o entendimento de que, na lógica das práticas, mais interfere os mecanismos culturais apreendidos no processo amplo de socialização do que os contributos teóricos meramente absorvidos no processo de formação. Não quero aqui referendar a desnecessidade da teoria na formação de professores, mas realçar que a teoria adquire significado no confronto com os problemas da prática. Há que se desenvolver nos processos formativos uma prática crítica do saber instituído. Com isso, quero concordar com Pimenta (1999) quando afirma que o conhecimento teórico não se adquire olhando, contemplando, ficando diante do objeto. Exige que se instrumentalize o olhar com teorias, estudos, olhares de outro sobre o objeto e, ainda mais, é preciso olhar esse existente como referência. Em outro escrito, Pimenta (2000) reforça essa questão do papel da teoria, ao afirmar que:

0 papel da teoria é of erecer aos professores perspectivas de análise para compreenderem os contextos históricos, sociais, culturais e de si mesmos como profissionais, nos quais se dá sua atividade docente, para neles intervir, transformando-os. (p. 92)

Nessa direção, reforço a questão da teoria necessária, pois isso é muito importante a considerar. Dialogando com Monteiro (2002), quando afirma que "a elaboração teórica é uma forma de visão de mundo, que é refeita e atualizada, por meio da reflexão, fazendo com que nossa compreensão sobre a prática, assim como todo o resto do que percebemos, seja alterada" (p. 119), quero realçar que o que discuto é a 'ilógica's dos mecanismos que fragmentam 0 saber da prática e o saber da pesquisa. Temos historicamente convivido com essa 'ilógica', na qual os supostos saberes da prática foram produzidos por pesquisadores que nem sempre consideraram as especificidades dessa prática. Assim, o que chega ao educador é um saber produzido e legitimado por outro. Quando 0 professor articula o saber pesquisado com sua prática, ele interioriza uma outra lógica que passa a dar mais significado ao que ele pode e deve realizar. Segundo Ghedin (2002), a pior violência é essa intencionalidade que separa teoria da prática. É uma violência, diz ele, "pois se rompe a possibilidade de manutenção da identidade humana consigo mesma". Diz o autor:

A atividade prática implica a modificação do ideal em face das exigências do próprio real. A prática requer um constante vai e vem de um plano para outro, o que só pode ser assegurado se a consciência se mostrar ativa ao longo de todo processo prático. Resulta disso que a atividade prática é inseparável dos fins que a consciência traça. (p. 134)

$\mathrm{Na}$ lógica das práticas, há emergência e urgência, e isso parece que não é privilégio das práticas educacionais no Brasil. Peter Woods (1999), inglês, fala das enormes pressões que estão recaindo sobre os ombros dos professores e diz que os professores não podem mudar de profissão nem a ordem social, então devem se acomodar. Acomodam-se por meio de estratégias de sobrevivência. Como diz Charlot (2006), primeiro sobreviver, depois ensinar e completa:

3. Conforme expressão de Ghedin (2002) para se referir à irracionalidade. 
Sua famosa resistência à mudança é talvez e antes de tudo, a expressão do sentimento de precariedade que [os docentes] experimentam: quando se vive equilibrando sobre um abismo, toda mudança é, antes de tudo, desestabilização, desorganização de estratégias de sobrevivência elaboradas a duras penas [...]. (p. 98)

Pude observar em várias circunstâncias, no trabalho com docentes no interior de escolas, que é realmente muito estranha, à primeira vista, essa relação do docente com sua prática. Observei muitas vezes que o professor nem sempre realiza na prática, o que pensa, o que discursa, o que teoriza. Ou seja, a prática mecanizada, não reflexiva, parece funcionar como um 'escudo' que impede que o novo desestabilize o 'fazer mínimo' que o professor está conseguindo fazer. Realmente ele defende sua estratégia de sobrevivência.

A impressão que se tem, muitas vezes, é que 0 professor abandona sua consciência ao entrar em situação prática. Assim ele não dimensiona exatamente que papel desempenha em situação prática ou o que realmente faz. Tenho muitos exemplos dessa situação em que o professor se admira de uma avaliação negativa que os alunos fazem sobre sua postura. Tenho me utilizado do recurso de gravação e auto-análise das práticas para começar a descongelar esses comportamentos que nem sequer poderiam ser chamados de comportamento prático. Dessa forma, nesses casos, a mera teoria, que muitos cursos insistem em transmitir, não tem nenhum espaço de fertilização e significação ao docente.

Imbert (2003) redireciona essa questão a partir da discussão da práxis pedagógica como instrumento de reavivar, desnaturalizar a escola e suas práticas. Este se apóia em Tosquelles (1984) para afirmar a diferença entre uma escola que opera por práticas arcaicas e aquela que introduz um projeto praxista em sua dinâmica. Diz o autor citado:

A práxis não é uma prática. Convém não se enganar a esse respeito. A práxis é elaboração coletiva, num grupo, das práticas vividas no quotidiano. A prática pode se situar no plano das elaborações primárias do pensamento, a práxis não. Ela pressupõe um coletivo: um coletivo articulado, nunca massificado ou aglutinado. (p. 74)

Imbert (2003) analisa que a mudança da escola e das práticas pedagógicas só poderá se realizar quando se operar uma transformação no imaginário dos educadores em sua dupla dimensão: ideológica e narcísica. Segundo o autor, a práxis visa à desocultação das articulações simbólicas e imaginárias da instituição. "Ela subverte o desconhecimento instituído no qual as pessoas e os coletivos perdem suas capacidades autônomas" (p. 73). Fica claro que a escola não se transforma por projetos inovadores, normalmente imposto às escolas por via burocrática. A escola só mudará quando os educadores, em coletivo, perceberem que a escola pode e deve ser outra.

A questão da práxis é para o autor a consolidação de um projeto de autonomia, que implica em trabalhar o imaginário sobre o qual a instituição se apóia. Trata-se, segundo ele, de re-historicizar a instituição.

Segundo o autor, e eu concordo, o motor da Pedagogia é a práxis pedagógica, que funciona como um instrumento de produção de autonomia, na direção de produzir sujeitos que falam. Nesse sentido, esse autor concorda com Hameline e Dardeline (1977) ao afirmar que "o objetivo da educação é exatamente, e em definitivo, que o 'eu' fale" (p. 94). Como vimos acima, segundo Ghedin (2002), a maior violência que se faz a um ser humano é impedir a atribuição de sentido às suas práticas, o que o despersonaliza e o desqualifica como identidade. Hameline nos convoca a produzir condições de prática que permitam que o sujeito fale, sinta, perceba, se coloque em diálogo com 0 mundo.

A perspectiva da práxis é a de uma ação que cria novos sentidos. Para tanto, há que se partir do pressuposto de que a busca de novos sentidos, a pretensão de autonomia, é própria 
do ser humano como um sujeito que se incomoda com seu inacabamento, conforme Paulo Freire e Charlot. A práxis como exercício pedagógico permite ao sujeito, como sujeito histórico e coletivo, acessar os caminhos de sua autonomia.

Tenho visto nas escolas, em que adentro para pesquisas, um quadro de autonomia perdida, perderam-na todos os envolvidos. A escola é formada por sujeitos calados, deprimidos, que se apropriam apenas de discursos alheios, manipuladores. Percebe-se na escola um panorama amorfo: todos cativos de um discurso que referenda o necessário fracasso da escola.

Para mudar a lógica das práticas, será preciso que os educadores assumam o projeto de autonomia da escola, na busca de que os 'eus' dos professores falem, que esses 'eus' reivindiquem uma nova escola, fruto das necessidades históricas e dos anseios de todos os educadores de nosso tempo.

Sabe-se que é preciso tempo e prudência para modificar as práticas pedagógicas amalgamadas historicamente. No entanto, a cultura escolar pode mudar, suavemente, com persistência e rigor político. Será preciso que o coletivo articulado de educadores organize novos pressupostos à lógica das práticas para dar contornos à emergência de uma nova práxis pedagógica.

A atividade docente adquirirá 0 sentido de práxis sempre que envolver as condições que são inerentes à própria docência:

- A explicitação e negociação de uma intencionalidade coletiva, que dirige e dá sentido à ação individual;

- O conhecimento do objeto que se quer transformar, na direção da intencionalidade coletivamente organizada;

- Intervenção planejada e científica sobre o objeto, com vistas à transformação da realidade social.

A atividade docente que se organiza de modo mecânico, casual, espontâneo, sem explicitação das intencionalidades, sem o conhecimento da realidade que se quer transformar, sem funcionar com vistas à transformação das condições de opressão, deixa de ser práxis educativa, deixa de ser atividade docente.

Para Kosik (1976), a práxis

[...] na sua essência e universalidade é a revelação do segredo do homem como ser autocriativo, como ser que cria a realidade (humano-social) e que, portanto, compreende a realidade (humana e não-humana, a realidade na sua totalidade). A práxis do homem não é atividade prática contraposta à teoria; é determinação da existência humana como elaboração da realidade. (p. 222)

Essas condições precisam ser compreendidas a partir da lógica das práticas, de forma que as práticas venham a se organizar como processos coletivos de autoformação e de transformação da realidade educativa.

Aprofundando essa questão que sempre me foi intrigante, já afirmei (Franco, 2002) que a riqueza de sentidos, a abundância de representações, a complexidade das intenções presentes nas práticas educacionais foram, por muito tempo, não consideradas, pois historicamente a Pedagogia estudou a educação pelos referenciais da ciência clássica, utilizando-se de reduções, de classificações padronizadas, tentando estudar os fenômenos por meio de relações de causalidade, priorizando análises meramente quantitativas e, com isso, desfigurando a complexidade da prática educativa.

Dessa forma, as teorias, os conhecimentos educacionais constituídos nem sempre expressaram a realidade complexa do fenômeno educativo. As teorias educacionais, muitas vezes, não traduziram o sentido implícito das práticas cotidianas e, assim, nem sempre impregnaram de compreensão o saber fazer dos educadores, dificultando sua utilização como suporte enriquecedor das ações práticas educativas e, com isso, houve sempre dificuldade em serem apropriadas ou incorporadas pelos sujeitos que a exercem.

Essa situação configura uma possível explicação da grande distância que foi se estabelecendo entre a teoria e a prática educativa. 
Ou seja, os estudos científicos sobre a educação, de cunho positivista, ao utilizarem olhares e suportes científicos, característicos de outras ciências, separaram sujeito e objeto de pesquisa, desprezaram as subjetividades inerentes à ação humana; distanciaram os interesses entre pesquisadores e pesquisados; recortaram artificialmente o contexto da pesquisa, deixando, portanto, de apreender a essência do sentido dessas práticas, congelando interpretações fragmentadas e sem sentido. Essas interpretações, captadas de forma parcial pelo olhar redutor dos pressupostos da ciência clássica, retiraram da cena educativa o significado original de suas práticas, expresso e vivido pelos protagonistas, impedindo que os resultados desse trabalho científico fossem percebidos pelos sujeitos, como expressão de sua ação.

Para melhor compreender o que pretendo expressar, faço minhas a fala do pedagogo Söetard (2004):

[...] as ciências da educação continuam sendo construções teóricas que não conseguem encontrar a passagem para 0 real e instru-mentar realmente a prática. (p. 51)

Sabe-se que, quando o sujeito não constrói sentido, ele não consegue realizar a apreensão cognitiva/emocional dos conhecimentos teorizados, os sujeitos não percebem uma relação entre os conhecimentos teóricos e suas ações cotidianas. $\mathrm{E}$ como vimos, na lógica das práticas, o componente existencial, emocional, afetivo é de fundamental importância para desracionalizar o excesso de teorias estéreis e desconectadas que têm fundamentado os processos formativos docentes.

\section{A lógic a da formação}

Concordo com Charlot (2006) que existem, pelo menos, quatro níveis de análise quando se discute a formação de professores:

a) A análise realizada por meio do saber como discurso constituído em sua coerência interna; b) A análise a partir da prática como atividade direcionada e contextualizada;

c) A análise da prática do saber como forma de mediação entre a prática e os discursos;

d) A análise do saber da prática sob forma de conhecimentos sobre a prática produzidos pela pesquisa.

Segundo Charlot (2006), formar professores é trabalhar os saberes e as práticas nesses diversos níveis e situar, a partir dos saberes e das práticas, as articulações possíveis entre as diferentes lógicas, que são e permanecerão heterogêneas. Segundo o autor, é fundamental essa questão da heterogeneidade, uma vez que a pretensão de integrar saberes e práticas em um único discurso ou em uma prática totalizante é fonte de dogmatismo e totalitarismo.

Acredito que esses quatro níveis podem ser sintetizados em dois focos:

a) Uma análise que se paute na mediação entre discursos e prática, articulada sob a forma de saberes pedagógicos (prática do saber);

b) Uma análise que se organize mediante a mediação entre prática, teoria e reflexão coletiva, expressa sob a forma de saberes docentes e pedagógicos (saber da prática).

Acredito, referendada em Charlot (2006), que esses dois níveis - a prática do saber e 0 saber da prática - podem estabelecer as mediações que articulem, de forma mais produtiva, as lógicas das práticas com a lógica da formação.

0 que se tem verificado em estudos recentes - como os de Borges (2004); Lisita (2006); Guimarães (2004); Formosinho (2002) - é que a lógica da formação de futuros professores tem se distanciado da lógica das práticas, o que referenda a fala de Lisita (2006) ao destacar a lógica da formação em relação à lógica das práticas:

Enquanto esta última se pauta pela necessidade de conhecer para atuar em situações complexas de ensino, a lógica da formação é regida por questões de conhecimento e 
se realiza mediante o esclarecimento de conceitos que compõem o conhecimento discursivo. Apesar de essa especificidade da lógica de formação por si só já se constituir em um elemento que a distancia da lógica das práticas, não é nela que residem as dificuldades de construir um processo de comunicação entre essas duas lógicas nos processos formativos. A dificuldade encontra-se na constituição da lógica da formação a partir de interesses e problemas vinculados às práticas institucionais acadêmicas, que não têm relação com as necessidades do exercício cotidiano do ensino ou que têm pouca repercussão sobre elas. (p. 111)

Em relação às práticas institucionais acadêmicas, a autora está se referindo, entre outros aspectos à lógica da estrutura curricular da universidade clássica, baseada em conhecimentos desvinculados das demandas cotidianas, na compartimentalização disciplinar; na excessiva fragmentação disciplinar; na organização do ensino a partir de aulas excessivamente expositivas; e ainda na desvinculação de saberes da prática e saberes científicos. Outros problemas semelhantes ocorrem em instituições de ensino menos clássicas como, por exemplo, a questão dos professores horistas, sem espaço para o trabalho coletivo, sem incentivo para a pesquisa. Quem trabalha com formação de docente precisa ter condições de trabalho compatíveis à necessária articulação do saber da prática, com as práticas de saber.

Outros autores (Borges, 2004; Lisita, 2006; Guimarães, 2004; Formosinho, 2002) referem-se também a esse distanciamento que os processos formativos impõem à prática docente. Tardif (2004) afirma que muitos pesquisadores não têm a intenção de abandonar suas pesquisas e investir fortemente no espaço de formação prática de futuros docentes. Day (2001) afirma que os professores consideram que a teoria ensinada nas universidades e escolas superiores de Educação é de valor reduzido e não podem ser aplicadas na prática de salas de aula e que os casos estudados na universidade são reduzidos e não propiciam uma aprendizagem de pensar sobre a prática. Sachs e Logan (1990) salientaram que há outros extremos ao lado da formação continuada de docentes: ao se tornarem excessivamente voltadas às necessidades da prática, esses cursos têm produzido mais a perda de destreza por parte dos professores:

Em vez de promover o desenvolvimento de práticos reflexivos, capazes de entender, questionar e transformar sua prática, a formação contínua, em sua forma atual, encoraja o desenvolvimento de professores que vêem o seu mundo em termos de objetivos instrumentais, que podem até ser alcançados através de receitas práticas do tipo experimentar e ver, legitimadas por experiências não analisadas ou pela aceitação acrítica de resultados de investigação. (p. 474, grifos meus)

Em pesquisas anteriores que realizei com alunos do curso de Pedagogia (Franco, 2001), pude verificar que os alunos em formação sentem muito o distanciamento da teoria e, mais que isso, a infertilidade da forma como os estudos teóricos são tratados. No caso da Pedagogia, essa dificuldade se amplia quando se considera que o corpo docente de tais cursos é, normalmente, formado por profissionais provenientes de diferentes áreas do saber e que nem sempre estão interessados em participar do processo formativo e, mais que isso, não organizam suas pesquisas com o foco nas práticas cotidianas escolares, na prática docente.

A ciência da Educação precisa perceber que é muito pouco oferecer, ao educador, teorias sobre fatos e normas observados, mas que será preciso auxiliar o educador "a perceber as exigências de cada situação educacional concreta, de tal forma que ele se torne apto a leválas a cabo autonomamente" (Schmied-Kowarzik, 1983, p. 50).

Theodor Litt, também comentado por Schmied-Kowarzik (1983), reafirma essa ques- 
tão, das necessidades de um professor em sua prática educativa, ao dizer que o professor precisa mais que um esclarecimento teórico, a posteriori, sobre sua práxis. Ele precisa mesmo de conhecimentos

[...] que atuem sobre a prática da educação [...], ofereçam ensinamentos, indiquem caminhos, apresentem objetivos à própria atividade do educador. (p. 51)

0 que tenho observado, nos diferentes cursos de licenciatura que já trabalhei e pesquisei, é que não há uma preocupação coletiva dos docentes da universidade em organizar uma formação que se estruture na dialeticidade dos saberes da prática com a prática dos saberes. São duas esferas dissociadas no processo formativo.

Pimenta e Lima (2004) consideram que os estágios curriculares poderiam funcionar como espaços formativos por excelência, articulador de pesquisas sobre as problemáticas específicas da profissão docente, envolvendo todas as disciplinas do curso em torno de um projeto político de formação de professores. No entanto, as autoras confirmam que o estágio, de um modo geral, na formação de docentes no Brasil, sempre foi identificado como a parte prática dos cursos de formação em contraposição à teoria. Essa contraposição reflete uma vez mais a dissonância entre as lógicas da formação e das práticas. As práticas só se tornarão instrumentos de formação quando, iluminadas pela teoria, se transformarem em objeto de pesquisa dos que as exercitam.

Zeichner (1997) acredita na possibilidade de os docentes serem co-autores da pesquisa pedagógica, ampliando assim a legitimidade das investigações desenvolvidas pelos próprios professores. 0 autor realça, especialmente, a questão da validade dialógica reflexiva, ou seja, a capacidade de a pesquisa promover o diálogo, a reflexão entre professores, de abrir espaços interativos para convivência crítica, para além da rotina e dos espaços burocraticamente organizados. Nesse sentido, cabe realçar que a pesquisa precisa deixar suas marcas não apenas na reflexão dos sujeitos, mas nos espaços administrativos que assim se transformarão em espaços pedagógicos.

\section{Os saberes pedagógicos como mediação}

Temos falado insistentemente em saberes docentes, em saberes pedagógicos. 0 que na realidade difere um saber de um fazer?

0 fazer, decorrente do tratamento da prática como tecnologia, é o exercício de uma ação mecânica, linear, inflexível, repetitiva. Para a reprodução de um fazer, não se necessita da articulação teoria e prática, não se requer um sujeito pensante e reflexivo, exige-se apenas 0 refinamento do exercício da prática. É por isso que muitas vezes afirmo, aos professores, que o mero exercício docente nem sempre produz saberes pedagógicos. Anos e anos de magistério pode produzir apenas a experiência de reproduzir fazeres, no mais das vezes, caducos e estéreis. Quando essa prática for mecanicamente estruturada, sob forma de reprodução acrítica de fazeres, ela não se transformará em saberes de experiência, pois a prática não foi vivenciada como práxis, não foi renovada nem transformada com as águas da reflexão, da pesquisa, da história. Se não houver o exercício da práxis que renove e rearticule a teoria e a prática, não haverá espaço para a construção de saberes. Nesse caso, tempo de serviço não se transforma em saber da experiência, pois esse reproduzir mecânico é anistórico e não cede espaço para a articulação dialética do novo e do necessário. Nessa situação, teoria e prática distanciam-se, assim como sujeito e ação não dialogam entre si.

Já um saber implica o exercício de uma prática reflexiva, comprometida, com sentido, com intencionalidade. Os saberes decorrem da práxis social, histórica, intencionada, realizada por um sujeito histórico, consciente de seus determinantes sociais, em diálogo com suas circunstâncias. Na práxis, sujeito e realidade dialogam, se transformam e são por ela transformados. É importante realçar que os saberes produzem conhecimentos, porque, prenhes de 
sentido, permitem e requerem a ação ativa e consciente do sujeito da ação sobre suas circunstâncias. Os saberes requerem a presença do sujeito intermediando a teoria com as condições da prática. Para tanto, os saberes não existem dissociados do sujeito, mas amalgamados a ele, como sujeito autônomo, consciente, criador, reflexivo e pesquisador.

Vale a pena refletir com Imbert (2003) a distinção que ele faz entre prática e práxis, reafirmando o que venho enaltecendo neste texto e atentando para a questão da autonomia e da perspectiva emancipatória, inerente ao sentido de práxis:

Distinguir práxis e prática permite uma demarcação das características do empreendimento pedagógico. Há, ou não, lugar na escola para uma práxis? Ou será que, na maioria das vezes, são, sobretudo, simples práticas que nela se desenvolvem, ou seja, um fazer que ocupa o tempo e o espaço, visa a um efeito, produz um objeto (aprendizagem, saberes) e um sujeito-objeto (um escolar que recebe esse saber e sofre essas aprendizagens), mas que em nenhum momento é portador de autonomia. (p. 15)

Portanto, só a ação docente, realizada como prática social, pode produzir saberes, saberes disciplinares, saberes referentes a conteúdos e sua abrangência social ou mesmo saberes didáticos, referentes às diferentes formas de gestão de conteúdos, de dinâmicas da aprendizagem, de valores e projetos de ensino.

Aquilo que antecede a possibilidade de produção de conhecimentos sobre a prática são os saberes pedagógicos, que permitem ao sujeito colocar-se em condição de dialogar com as circunstâncias, de compreender as contradições, de articular teoria e prática. É possível, portanto, se falar em saberes pedagógicos como a possibilidade de criar, na prática, conhecimentos sobre a condução, a criação e a transformação dessas mesmas práticas.

0 saber pedagógico só pode se constituir a partir do próprio sujeito, que deverá ser formado como alguém capaz de construção e de mobilização de saberes. A grande dificuldade em relação à formação de professores é que se quisermos ter bons professores, teremos que os formar como sujeitos capazes de produzir ações e saberes, conscientes de seu compromisso social e político. Não dá para formar professores como objetos dotados de habilidades e competências, instaladas de fora para dentro, sob forma de fazeres descobertos por outros, que nada significam na hora da prática. Sintetizo com a afirmativa de Imbert (2003): "o movimento em direção ao saber e à consciência do formador não é outro senão o movimento de apropriação de si mesmo" (p. 27).

Quem trabalha com formação de professores está cansado de verificar o desespero de professores frente ao próprio despreparo profissional: saem da faculdade sem saber como organizar um bom começo de prática docente; saem dos cursos de formação continuada sem coragem de empreender mudanças na prática; ou seja, não conseguem apreender saberes básicos nem conseguem estar em processo de construção dos saberes pedagógicos.

Quando tenho conversado com formadores sobre essa questão da construção de saberes pedagógicos, é comum que me interpelem dizendo que tais conhecimentos/saberes não são palpáveis, ou seja, solicitam detalhamento de processos de formação de docente para a construção de saberes pedagógicos.

Minha perspectiva é a de que os saberes pedagógicos só são possíveis em um sujeito que vai gradativamente assumindo uma posição política frente ao compromisso de ser professor, engajando-se criticamente em suas circunstâncias, cercando e acercando-se de sua realidade existencial, transformando-a em direção às suas intencionalidades. Assim posicionado, esse sujeito vai fazer uso do necessário conhecimento didático, metodológico, cultural, servindo-se desse aparato teórico-prático, para ir construindo em ação seus saberes disciplinares, didáticos, metodológicos. A capacidade de articular 0 aparato teórico-prático, a capacidade de mobilizá- 
Io na condição presente, a capacidade de organizar novos saberes a partir da prática, essas capacidades em conjunto, estruturam o que chamo de saberes pedagógicos.

Para melhor firmar o que expresso, respaldo-me nas observações de duas pesquisadoras chilenas Abraham e Lavin (2004):

...partimos del señalamento que el saber pedagógico lo va construyendo el sujeto, en su interacción con la instituición formadora y, posteriormente, en su quehacer profisional [...]. Desde nuestra perspectiva los saberes pedagógicos son una estructura articulada de concepciones, fundamentos, experiencias y metodologias que conforman el conocimiento del docente, otorgan identidad a su quehacer y se incorporan y se construyen en la pratica pedagógica. Son, en definitiva, saberes que estruturan el conocimiento del profesional y dan sentido y significado a su práctica cotidiana. (p.13)

Considero importante o fato de as autoras referirem-se aos saberes pedagógicos como saberes estruturantes do conhecimento profissional, que outorgam identidade e que são processuais, vão se constituindo nos caminhos da prática. São saberes dialogantes, reflexivos e que, portanto, não cabem em pacotes prontos de cursos avulsos de formação.

Essas asserções reafirmam também que processos de formação não podem se realizar de forma abreviada, superficial, pois se trata de formar, nos futuros docentes, posturas de compromisso, engajamento, crítica e envolvimento com o mundo e a profissão.

Afirmo serem os saberes pedagógicos construções cognitivas, realizadas pelos professores a partir de sua prática cotidiana, que é significada, inicialmente, por conhecimentos pedagógicos prévios, que se organizam sob forma de concepções e pressupostos, sobre os sentidos de ser e de estar professor.

Os conhecimentos pedagógicos são construções teóricas, elaboradas por pesquisadores da área, que se organizam sob forma de teorias ou preceitos e que são apropriados pelos docentes, quer sob a forma de estudos ou pesquisa, quer sob a forma de generalizações teóricas do senso comum. Essa questão dificulta a compreensão do sentido de conhecimento pedagógico, uma vez que quem circula e pesquisa no cotidiano das salas de aulas percebe que as práticas escolares, muitas vezes, organizam-se em torno de teorias que não são, necessariamente, aquelas produzidas pelas ciências da Educação, especialmente, a Pedagogia4.

Essa questão da dissonância entre as teorias que estão presentes na prática e as teorias produzidas pelas ciências da Educação realça que a teoria pedagógica, historicamente construída, nem sempre se fundamentou na compreensão da realidade das práticas educativas. Dissonâncias que se explicitam na dessintonia entre a lógica das práticas e a lógica da formação.

\section{Saberes da formação}

Uma preocupação que está sempre presente nos formadores de docentes é como formar os futuros professores para que saibam construir, no processo da prática, saberes docentes e, mais que isso, como formar docentes que saibam mobilizar os conhecimentos pedagógicos na transformação de suas práticas e dos próprios saberes que vão sendo percebidos como ultrapassados ou inadequados para algumas situações. Essa questão não vai ser resolvida nesse final de artigo, mas será apenas anunciada como perspectiva.

Houssaye (2004) pondera sobre as possibilidades de os saberes serem desenvolvidos na formação de docentes e o autor chega a afirmar que a experiência é fundamental a um aprendiz de docente, mas uma experiência que contenha pelo menos três elementos:
a) Um saber do saber fazer;
b) Um saber para o saber fazer;
c) Um saber a partir do saber fazer.

4 . Ver nesse sentido os estudos de Becker (1995) sobre a epistemologia do professor. 
Quero realçar que não acredito que uma instituição formadora possa transmitir saberes a outrem, mas acredito que há processos de formação que abrem espaços para que os formandos se coloquem em processos de autoformação, estruturando uma nova relação do sujeito com o saber ${ }^{5}$.

Nesse sentido, já escreveu Pimenta (1999) que o futuro profissional não pode constituir seu saber fazer senão a partir de seu próprio fazer. E ainda reafirma a autora: "não é senão sobre esta base que 0 saber, enquanto elaboração teórica se constitui" (p. 26).

Houssaye (2004) e Pimenta (1999) concordam que a base para a formação de docentes deverá ser o próprio fazer profissional e essa última ainda afirma que "os saberes sobre a educação e sobre a pedagogia não geram os saberes pedagógicos. Esses só se constituem a partir da prática, que os confronta e reelabora" (p. 26). Será necessário, portanto, que os processos de formação não exponham apenas os formandos à prática, mas que trabalhem os confrontos que a prática suscita.

A distinção das três formas de saber organizada por Houssaye (2004) evidencia que existe um saber fazer da profissão docente, visto mesmo sob a forma de conhecimentos pedagógicos e que pode conter o conhecimento sobre os métodos e as técnicas do ensino, mas ele se refere a um saber do saber fazer e isso faz toda diferença. Essa sua afirmação pressupõe 0 papel ativo, crítico e reflexivo do professor sobre o conhecimento disponível sobre os fundamentos da prática. Esse saber seria a capacidade de o sujeito professor afirmar: nessa aula, usei esse procedimento e isso produziu tal conseqüência. Ou seja, um saber do saber fazer implica um sujeito que fala, observa, critica o uso de procedimentos da prática.

Um saber para o saber fazer implica a possibilidade de o sujeito lançar hipóteses sobre práticas prováveis; planejar procedimentos para um incidente específico; analisar práticas alheias.

Um saber a partir do saber fazer também é diferente de saber fazer simplesmente. Nesse caso, refiro-me a um sujeito que aprende a olhar a própria prática; aprende a refletir sobre ela; aprende a buscar alternativas à sua transformação; percebe a adequabilidade ou inadequação de práticas cotidianas; coloca em estranhamento procedimentos familiares; e acostuma-se a buscar o novo. Esses saberes propiciarão ao decente realizar teorizações sobre a articulação teoria e prática, ou seja, aprender a pedagogizar a própria prática.

Considero que os processos de formação precisam considerar a estruturação de uma experiência formativa, experiência essa que não apenas mostra a prática, transmite teorias e discursa sobre a profissionalização. Essa experiência precisa colocar o sujeito em processos de diálogos com a realidade, diálogos formativos com sua própria identidade, diálogos que formarão capacidades de reelaboração reflexiva a partir das contradições da existência vivenciada.

Para se entender essa experiência formativa, é preciso considerar, como o faz Houssaye (2004), a dimensão da experiência no sentido experencial, em detrimento da dimensão experimental. Segundo o autor, a dimensão experimental funda-se no paradigma positivista que, nesse caso, pressupõe que experimentar é saber aplicar. J á a dimensão experencial fundamenta-se no pressuposto herme-nêutico que, nesse caso, passa a considerar a experiência como busca de sentido.

\section{Algumas perspectivas}

A história brasileira com formação de docentes utilizou-se sempre dos estágios para complementar o currículo de formação de professores, mas tais estágios foram sempre vistos na dimensão experimental: pressupunha-se que primeiro se aprende a teoria e depois se aplica na prática. Essa fórmula já está teoricamente desgastada, no entanto, na prática, ainda continua a fundamentar a formação de nossos docentes.

5 . Vide Charlot (2000): a relação com o saber é relação de um sujeito com o mundo, com ele mesmo e com outros. É relação com o mundo como conjunto de significados, mas também como espaço de atividades e se inscreve no tempo. 
0 estágio, segundo Pimenta e Lima (2004), pode ser um amplo recurso para produção de saberes profissionais se funcionar como espaço de pesquisa desde o início do curso, de modo a possibilitar que os professores em formação e os professores universitários desenvolvam, em parceria, estudos e pesquisas que se revertam em benefício da aprendizagem profissional dos professores, da produção de conhecimentos sobre a Educação e da melhoria do ensino nas escolas-campo em que se realizam tais estágios. As autoras relatam diversas experiências e modalidades sob as quais os estágios com pesquisas poderiam se realizar: a) mobilizando-se resultados de pesquisas para ampliar a compreensão das problemáticas do ensino; b) realizando-se projetos para estudar os fundamentos da Educação e do ensino e suas manifestações nas escolas; c) desenvolvendo-se 0 estágio mediante projetos de pesquisas dos professores universitários e dos professores em formação; d) realizando-se pesquisas colaborativas em parceria entre professores universitários e professores das escolas; e) concebendo-se o estágio dentro do currículo de formação, como um projeto de pesquisa ao longo de cada semestre, envolvendo várias disciplinas do curso; entre outras.

Ainda em relação à ressignificação dos estágios, como forma de articular as duas lógicas que aqui tratei, há a proposta de Ghedin, Brito e Oliveira (2006) que relatam experiência que vêem realizando na universidade estadual do Amazonas, onde consolidam um modelo de estágio centrado na pesquisa, ao longo da formação inicial de professores para as séries iniciais do Ensino Fundamental. Consideram como condições metodológicas fundamentais: a) observação fenomenológica no intuito de suspender os preconceitos, na busca de superar o 'criticismo vazio'; b) o registro atento de situações e acontecimentos com vistas a um pro- cesso de diagnóstico, dinâmico e vivo da realidade escolar; c) a superação fragmentada dos problemas da escola na busca de uma perspectiva interdisciplinar para a construção do conhecimento; e d) atividades na direção do autoconhecimento do profissional da Educação com objetivo de superação da indiferença e do conformismo diante das situações- problema.

Essas propostas vão demonstrando, acima de tudo, que as instituições de formação de docentes precisam se transformar em seus tempos, em seus processos formativos, construindo uma nova configuração de espaço de aprendizagem cooperativa, que articule vida e formação, sujeito e coletivo, intencionalidades e práticas, conforme já escrevi (Abdalla e Franco, 2003) ao relatar a experiência que realizamos com a estruturação de um modelo de supervisão contínua de formação em um curso de Pedagogia na cidade de São Paulo:

\section{O diálogo de novos espaços, com os dife- rentes mecanismos de formação, foram permitindo um processo de multiformação, que passava a impregnar a cultura local, realçando a pertinência da pesquisa e a presença contínua da reflexão coletiva, nos menores movimentos de decisão, de elabo- ração e de leitura do cotidiano. (p. 87)}

Será preciso, enfim, que os processos formativos de docentes absorvam a dimensão experencial, não mais separando teoria e prática, mas mergulhando, desde o início, o aluno e o formador em situação de mediação dos confrontos da prática, buscando a significação das teorias. Só assim será possível fazer o exercício fundamental da Pedagogia: criar articulações cada vez mais profundas entre a teoria e a realidade. Ou seja, fazer dialogar a lógica das práticas com a lógica da formação. Essa é a grande tarefa que os cursos de formação devem enfrentar. 


\section{Referências bibliográfic as}

ABDALLA, M. F.; FRANCO, M. A. S. Formando para uma nova epistemologia da prática. Revista de educação CEAP, Salvador: Bahia, v. 43, n. 11, p. 79-87, 2003.

ABRAHAM N.; LAVIN, H. S. Los processos de formación pedagógica em instituiciones formadoras de docentes. Investigación Fondecyt, PIIE, Chile, 1994.

BECKER, F. Epistemologia do professor. São Paulo: Cortez, 1995.

BORGES, C. M. F. 0 professor da educação básica e seus saberes profissionais. Araraquara: J M, 2004.

CARR, W. Una teoria para la educatión: hasta una investigatión educativa critica. Madri: Morata, 1996.

CHARLOT, B. Da relação com o saber: elementos para uma teoria. Porto Alegre: Artes Médicas, 2000. $19 \overline{9} 0$.

. Enseigner, former: logique des discours constitués et logique des pratiques. Recherche et formation. Paris. v. 8, out.,

. Relação com o saber, formação de professores e globalização. Porto Alegre: Artes Médicas, 2006.

CUNHA, M. I. Profissionalização docente: contradições e perspectivas. In: VEIGA, I. P.; CUNHA, M. I. (Orgs.). Desmistificando a profissionalização do magistério. Campinas: Papirus, 1999. p. 127-148.

0 bom professor e sua prática. Campinas: Papirus, 1989.

DAY, C. Desenvolvimento profissional de professores. Porto: Porto Editora, 2001.

FORMOSINHO, J . A universidade e a formação de educadores de infância: potencialidades e limites. In: MACHADO, M. L. A. (Org.). Encontros e desencontros em educação infantil. São Paulo: Cortez, 2002, p. 169-188.

FRANCO, M. A. S. Investigando a práxis docente: dilemas e perspectivas. In: AFIRSE: Association Francophone Internacionale de Recherche Scientifique en éducation, 2002, Lisboa. Livro do Colóquio: a formação de professores à luz da investigação. Lisboa: Faculdade de Psicologia e Ciências da Educação. Universidade de Lisboa, 2002. p. 187-187.

A pedagogia como ciência da educação. In: 24ạ Reunião da ANPED, 2001, Caxambu, 2001. Disponível em <www. anped.org.br/24/sessesp.htm>. CD-ROM.

Coordenação pedagógica: uma práxis em busca de sua identidade. Educativa: Revista do Departamento de Educação da UCG, v. 8, n. 1, p. 125-138, jan./jul. 2005.

. Saberes pedagógicos e prática docente. In: ENDIPE: Educação formal e não formal, processos formativos e saberes pedagógicos. 13. Anais... v. 1, p. 27-50, Recife, 2006.

. Indicativos para um currículo de formação de pedagogos. In: VANILTON, R. S. (Org.). Políticas organizativas e curriculares, educação inclusiva e formação de professores. Rio de J aneiro: DP\&A, 2002. p. 173-189.

. Para um currículo de formação de pedagogos: Indicativos. In: PIMENTA, S. G. (Org.). Pedagogia e pedagogos: caminhos e perspectivas. São Paulo: Cortez, 2002.

. A pedagogia como ciência da educação. Campinas: Papirus, 2003.

Nas trilhas e tramas de uma escola pública: abordagem fenomenológica de um relato de experiência. 1996. Dissertação (Mestrado)- Pontifícia Universidade Católica de São Paulo. São Paulo. 1996.

GHEDIN, E. Professor reflexivo: da alienação da técnica à autonomia da crítica. In: GHEDIN, E.; PIMENTA, S. (Orgs.). 0 professor reflexivo no Brasil: gênese e crítica de um conceito. São Paulo: Cortez, 2002. 
GHEDIN, E.; BRITO, C.; OLIVEIRA, N. O espaço pedagógico da formação docente: relato de uma experiência no Curso Normal Superior. In: ENDIPE. 2006. Políticas educacionais, tecnologias e formação do educador: repercussões sobre a didática e as práticas de ensino. Recife: ENDIPE, 2006.

GUIMARÃES, V. S. Formação de professores: saberes, identidade e profissão. Campinas: Papirus, 2004.

HAMELINE, D. ; DARDELINE, M-J . La liberté d'apprendre: situation II. Paris: Les Editions Ouvriéres,1977.

HOUSSAYE, J. Pedagogia: justiça para uma causa perdida? In: HOUSSAYE, J. et al. Manifesto a favor dos pedagogos. Porto Alegre: Artmed, 2004.

IMBERT, F. Para uma práxis pedagógica. Brasília: Plano, 2003.

LISITA, V. Didática e formação de professores: um estudo sobre as possibilidades da reflexão crítica. 2006. Tese (Doutorado em Educação)- Universidade de São Paulo. São Paulo. 2006.

MONTEIRO, S. B. Epistemologia da prática: o professor reflexivo e a pesquisa colaborativa. In: GHEDIN, E.; PIMENTA, S. (Orgs.). 0 professor reflexivo no Brasil: gênese e crítica de um conceito. São Paulo: Cortez, 2002.

PIMENTA, S. G. (Org.). Saberes pedagógicos e atividade docente. São Paulo: Cortez, 2000.

Professor: formação, identidade e trabalho docente. In: . (Org.). Saberes pedagógicos e atividade docente. São Paulo: Cortez, 2000, p. 15-34.

. (Org.). Didática e formação de professores: percursos e perspectivas no Brasil e em Portugal. São Paulo: Cortez, 1997.

. A prática (e a teoria) docente ressignificando a Didática. In: OLIVEIRA, M. R. N. S. (Org.). Confluências e divergências entre didática e currículo. Campinas: Papirus, 1998.

0 estágio na formação de professores: unidade, teoria e prática? São Paulo: Cortez, 1996.

- A didática como mediação na construção da identidade do professor: uma experiência de ensino e pesquisa na licenciatura. In: ANDRÉ, M.; OLIVEIRA, M. R. N. S. Alternativas do ensino de didática. Campinas: Papirus, 1997. $\overline{1} \overline{9} \bar{q}$.

Educação, pedagogia e didática. In: ENCONTRO NACIONAL DE DIDÁTICA E PRÁTICA DE ENSINO. 7. Goiânia, p. 44-64,

(Org.). Pedagogia e pedagogos: caminhos e perspectivas. São Paulo: Cortez, 2002.

PIMENTA, S. G.; GHEDIN, E. (Orgs.). Professor reflexivo no Brasil: gênese e crítica de um conceito. São Paulo: Cortez, 2002.

PIMENTA, S. G.; LIMA, M. S. L. Estágio e docência. São Paulo: Cortez, 2004. 196 p. (Coleção docência em formação. Série saberes pedagógicos)

SACHS, J.; LOGAN, L. Control or development? A study of inservice education. J ournal of Curriculum Studies, v. 22, n. 5, p. 473 481. London, 1990.

SACRISTÁN, G. Consciência e ação sobre a prática como libertação profissional de professores. In: NÓVOA, A. (Org.). Profissão professor. Porto: Porto Editora, 1999.

SCHMIED-KOWARZIK, W. Pedagogia dialética: de Aristóteles a Paulo Freire. São Paulo: Brasiliense, 1983.

SÖETARD, M. Ciência(s) da educação ou sentido da educação? A saída pedagógica. In: HOUSSAYE, J . et al. Manifesto a favor dos pedagogos. Porto Alegre: Artmed, 2004.

TARDIF, M. Saberes docentes e formação profissional. Petrópolis: Vozes, 2004.

TOSQUELLES, F. Éducation et psycothérapie institutionelle. Mantes-la-Ville. Hiatus, 1984. 
WOODS, P. Aspectos sociais da criatividade do professor. In: NÓVOA, A. (Org.). Profissão professor. Porto: Porto Editora, 1999.

ZEICHNER, K. 0 professor reflexivo. In: Reunião Nacional da ANPED. 1997. Caxambu. Conferência... Caxambu: Minas Gerais, 1997.

Recebido em 11.07.07

Aprovado em 12.12 .07

Maria Amélia Santoro Franco, pedagoga, doutora em Educação pela Universidade de São Paulo, é coordenadora do Programa de Mestrado em Educação da Universidade Católica de Santos. Dentre suas publicações sobre Pedagogia e pesquisa em Educação, realça-se o livro Pedagogia como Ciência da Educação, (Papirus, 2003 - esgotado), que está sendo reeditado pela Cortez (2008). 